\title{
p19Arf sensitizes B16 melanoma cells to interferon- $\beta$ delivered via mesenchymal stem cells in vitro
}

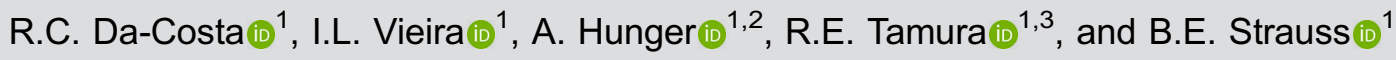 \\ ${ }^{1}$ Viral Vector Laboratory, Centro de Investigação Translacional em Oncologia/LIM24, Instituto do Câncer do Estado de São Paulo, \\ Faculdade de Medicina, Universidade de São Paulo, São Paulo, SP, Brasil \\ ${ }^{2}$ Biotecnologia Unidade 1, Cristália Produtos Químicos Farmacêuticos, Itapira, SP, Brasil \\ ${ }^{3}$ Departamento de Ciências Biológicas, Universidade Federal de São Paulo, Diadema, SP, Brasil
}

\begin{abstract}
The immune stimulatory and anti-neoplastic functions of type I interferon have long been applied for the treatment of melanoma. However, the systemic application of high levels of this recombinant protein is often met with toxicity. An approach that provides localized, yet transient, production of type I interferon may overcome this limitation. We propose that the use of mesenchymal stem cells (MSCs) as delivery vehicles for the production of interferon- $\beta$ (IFN $\beta$ ) may be beneficial when applied together with our cancer gene therapy approach. In our previous studies, we have shown that adenovirus-mediated gene therapy with IFN $\beta$ was especially effective in combination with p19Arf gene transfer, resulting in immunogenic cell death. Here we showed that MSCs derived from mouse adipose tissue were susceptible to transduction with adenovirus, expressed the transgene reliably, and yet were not especially sensitive to IFN $\beta$ production. MSCs used to produce IFN $\beta$ inhibited B16 mouse melanoma cells in a co-culture assay. Moreover, the presence of p19Arf in the B16 cells sensitizes them to the IFN $\beta$ produced by the MSCs. These data represent a critical demonstration of the use of MSCs as carriers of adenovirus encoding IFN $\beta$ and applied as an anticancer strategy in combination with p19Arf gene therapy.
\end{abstract}

Key words: Gene therapy; Immunotherapy; Stem cell therapy; Adenovirus; p53; Interferon- $\beta$

\section{Introduction}

Cancer therapy using recombinant cytokine proteins has been shown to mediate antineoplastic effects, but may present toxicity when high level systemic administration is used. In the case of type I interferon, the recombinant protein is expected to promote innate and adaptive anti-tumor immune responses, induce apoptosis in cancer cells, and inhibit angiogenesis (1). Interferon (IFN) $\alpha$ therapy was approved by the US Food and Drug Administration (FDA) in 1995, and it has been shown to reduce melanoma tumor burden and prolong survival in some patients (2). The short half-life of IFN $\alpha$ limits therapeutic activity and, thus, high levels of recombinant protein are required. However, a high systemic dosage of IFN $\alpha$ is associated with adverse effects including myalgia, pyrexia, and depression (3).

Alternatively, a variety of gene transfer methods may be employed in order to achieve high local concentration of type I interferon while avoiding systemic toxicity. Such approaches include the intratumoral application of nonreplicating viral vectors, use of armed oncolytic viruses or even mesenchymal stem cells (MSCs) as carriers of vectors encoding type I interferon (1). For the latter, autologous
MSCs may be isolated from the circulation, bone marrow, or adipose tissue, including lipoaspirates, cultivated in the laboratory, modified and expanded ex vivo, and then infused in the patient (4-6). The use of MSCs as a delivery vehicle for the therapeutic payload has been shown to home to and infiltrate the tumor site where they provide therapeutic transgene levels while shielding the gene transfer vector from immune recognition (7-11).

In our previous studies, we have shown that direct intratumoral delivery of an adenoviral vector encoding IFN $\beta$ inhibits tumor progression $(12,13)$. Moreover, the association of IFN $\beta$ gene transfer along with p19Arf (alternative reading frame of the Cdkn2a gene, p19Arf in mice, p14ARF in humans) brought the added benefit of immunogenic cell death and the combined, but not individual, treatments served as an immunotherapy (1214). The role of p19Arf is to block the interaction of Mdm2 with p53, sparing p53 from ubiquitination and subsequent degradation, thus promoting its activation and tumor suppressor function (15). The type I interferon and p53/ p19Arf pathways are known to cooperate in the induction of anti-viral defense and cell death $(16,17)$. In addition,

Correspondence: B.E. Strauss: <bstrauss@usp.br>

Received June 3, 2019 | Accepted December 2, 2019 
the adenoviral vectors used, AdRGD-PG, were modified to contain improvements at both the transductional (RGDmodified fiber protein) and transcriptional levels (p53responsive chimeric promoter, PG) (13). In this way, the vector and transgenes are expected to work together to promote high level expression, cell death, and anti-tumor immune modulation, points that have been substantiated previously $(18,19)$.

Here, we explored a novel approach to the use of IFN $\beta$ plus p19Arf gene transfer. MSCs derived from mouse adipocyte tissue were transduced with AdRGD-PG-IFN $\beta$ and used to deliver this secreted, immune modulatory protein to mouse melanoma cells in vitro. We showed that MSCs tolerate IFN $\beta$ production relatively well, while B16 melanoma cells were inhibited in the presence of the IFN $\beta$ produced by the MSCs. Moreover, B16 cells previously treated with the AdRGD-PG-p19Arf vector were further sensitized to the effects of IFN $\beta$ produced by MSCs. These assays suggested that MSCs may be an interesting vehicle for the delivery of IFN $\beta$ to tumor cells, especially in combination with p19Arf gene transfer.

\section{Material and Methods}

\section{Cell culture}

The B16F10 mouse melanoma cells (referred to simply as B16) were kindly provided by Roger Chammas (ICESP, FM-USP) and verified as per Hunger et al. (13). The B16 cells were cultivated in RPMI containing a 1× concentration of the commercial product Antibiotic-Antimycotic and $10 \%$ fetal calf serum (FBS) (all products from Thermo Fisher, USA). To generate the B16-GFP cell line, B16 cells were transduced with Lego-G/puro-opt (kindly provided by Kristoffer Reicken, University Medical Center, Germany) at a MOI of 1 and then selected for puromycin resistance as per Vieira et al. (20).

\section{Isolation and cultivation of MSC}

All animal procedures were evaluated and approved by the Commission for the Ethical Use of Animals (CEUA) of FM-USP, protocol 177/14. Animals were supplied by the Biotério Central (FM-USP) and housed at the Biotério Experimental, Centro de Medicina Nuclear (CMN, FM-USP). The animals used were 6 -week-old male C57BL/6 mice, that were allowed access to food and water ad libitum.

For MSC isolation, a single animal was euthanized by $\mathrm{CO}_{2}$ inhalation and immediately subcutaneous adipose tissue (AT) was collected and washed with $1 \times$ phosphate buffered saline (PBS) containing $2.5 \times$ antibiotic-antimycotic (Thermo Fisher). Then, the AT was incubated in the presence of $0.075 \%$ collagenase 1 (Sigma-Aldrich, USA) diluted in $1 \times \mathrm{PBS}$ for $30 \mathrm{~min}$, at $37^{\circ} \mathrm{C}$ with agitation before adding Dulbecco's modified Eagle medium - Nutrient Mixture F-12 (DMEM/F-12) containing 20\% FBS (Thermo Fisher). The treated AT was then pelleted (300 $\mathrm{g}, 10 \mathrm{~min})$ before resuspension in fresh medium (DMEM/F12, 20\%
FBS) and transferred to culture dishes. At $48 \mathrm{~h}$ intervals, the supernatant and non-adherent cells were discarded and the adherent cell population was washed with $1 \times$ PBS and fresh medium was added, until $80 \%$ confluence was reached. Cells were then trypsinized using TrypLE (Thermo Fisher). This yielded approximately $4 \times 10^{6} \mathrm{MSC}$ at passage 3 . We observed that at each passage, the cells had doubled 2 to 3 times. This permitted the cryopreservation of 6 vials, each with approximately $1 \times 10^{6}$ cells at passage 4 . These could then be thawed and expanded as needed for the assays performed at passage 5 or 6 .

\section{Cell surface markers}

MSCs, $1 \times 10^{5} / 1.5 \mathrm{~mL}$ tube, were stained with the antibodies indicated in Supplementary Table S1 using a $1: 100$ dilution in $1 \times$ PBS containing $1 \%$ bovine serum albumin (BSA) at $4^{\circ} \mathrm{C}$ for $30 \mathrm{~min}$ in the dark. Then, the cells were washed three times with $1 \times$ PBS before flow cytometry (Attune, Thermo Fisher) and analyzed using the Attune Cytometric Software.

\section{Differentiation}

The MSCs were plated, $1 \times 10^{4}$ cells/well in 6-well dishes, and cultivated until reaching $50 \%$ confluence. Then, the specific differentiation medium (StemPRO, Thermo Fisher) was added and the cells were incubated before staining to reveal the cell type. For adipogenesis, incubation was carried out at $37^{\circ} \mathrm{C}$ for 14 days before fixation with paraformaldehyde and staining with Oil Red O (Sigma-Aldrich). For chondrogenesis, after 14 days of incubation at $37^{\circ} \mathrm{C}$, the cells were treated with toluidine blue (Sigma-Aldrich) before washing and successive fixation steps using $70 \%, 90 \%$, and absolute ethanol. In the case of osteogenesis, the cells were incubated at $37^{\circ} \mathrm{C}$ for 21 days before adding $1 \%$ silver nitrate and treating with UV light for 45 min, washing, treating with $3 \%$ sodium thiosulfate, and finally adding Van Gieson stain (Merck, Germany), and then washing with absolute ethanol.

\section{Vectors, production, and titration}

The AdRGD-CMV-LacZ vector was kindly provided by Dr. Hiroyuki Mizuguchi (Osaka University, Japan) (21). The AdRGD-PG-eGFP, AdRGD-PG-p19, and AdRGDPG-IFN $\beta$ vectors encoding enhanced green fluorescent protein (GFP), mouse p19Arf, or mouse IFN $\beta$, respectively, have been described previously (12-14). Virus production was performed using iodixanol gradient centrifugation $\left(209,627 \mathrm{~g}, 1\right.$ hour, $\left.10^{\circ} \mathrm{C}\right)(22)$ and titration was performed using the AdenoX Rapid Titer kit (Clontech, USA). The biological titer, reported as infectious virus particles (IVP)/mL, was used to calculate the multiplicity of infection (MOI).

\section{Transduction}

When working in 6-well dishes, $5 \times 10^{4}$ cells/well were plated and allowed to incubate at $37^{\circ} \mathrm{C}$ for $24 \mathrm{~h}$. 
Then, the medium was removed and replaced with fresh medium containing $2 \%$ FBS plus the virus stock, using a total volume of $600 \mu \mathrm{L}$. After $4 \mathrm{~h}$ incubation at $37^{\circ} \mathrm{C}$, the medium was removed and replaced with $2 \mathrm{~mL}$ fresh DMEM/F12, 20\% FBS.

To control for total $\mathrm{MOI}$ used where co-transduction of vectors encoding $\mathrm{p} 19 \mathrm{Arf}$ and IFN $\beta$ was performed, the $\mathrm{MOI}$ of the GFP condition was equal to the total MOI of the co-transduction. Where p19Arf or IFN $\beta$ viruses were to be used separately, the total $\mathrm{MOI}$ was completed with the GFP vector. In this way, MOls and gene dosages were always equal across all conditions.

\section{Detection of GFP by flow cytometry}

After $24 \mathrm{~h}$ of incubation post-transduction, cells were trypsinized, washed with $1 \times$ PBS, and resuspended in $1 \mathrm{~mL}$ of $1 \times$ PBS before observation (Attune, Thermo Fisher), and analyzed using the Attune Cytometric Software.

\section{ELISA for the quantification of mouse IFN $\beta$}

MSCs were transduced as described above and supernatant was collected $48 \mathrm{~h}$ post-transduction and stored at $-80^{\circ} \mathrm{C}$. ELISA was performed using the mouse IFN $\beta$ kit from PBL Biomedical (USA) and absorbance at $450 \mathrm{~nm}$ was analyzed using a Victor plate reader (PerkinElmer, USA).

\section{MTT assay}

MSCs were plated in 96-well plates, $1 \times 10^{3}$ cells/well, and the next day transduced with the adenoviral vectors. The plates were then incubated for 24,48 , or $72 \mathrm{~h}$ before adding $5 \mathrm{mg} / \mathrm{mL}$ MTT in PBS, incubating at $37^{\circ} \mathrm{C}$ for $4 \mathrm{~h}$ then solubilizing the converted substrate using $20 \%$ SDS/ $50 \%$ DMF, pH 4.7. The next day, absorbance at $570 \mathrm{~nm}$ was examined using a Victor plate reader (Perkin-Elmer). Each experimental condition was performed in quadruplicate and the biological assays were performed on three independent occasions.

\section{Co-culture assays}

MSCs were plated in 6-well dishes and transduced during $6 \mathrm{~h}$ before washing three times with $1 \times$ PBS. Next, the MSCs were trypsinized and counted. In parallel, the B16-GFP cells were also transduced as indicated, incubated at $37^{\circ} \mathrm{C}$ for $6 \mathrm{~h}$, washed, collected, and counted. Then, equal proportions of each cell line $\left(1 \times 10^{4}\right.$ cells/line $)$ were seeded together in 6-well dishes in DMEM/F12 and $20 \%$ FBS. Ten random fields were photographed (EVOS $\mathrm{FL}$, Thermo Fisher) at the indicated time points and the fluorescent (B16-GFP) or non-fluorescent (MSC) populations were manually counted with the assistance of Image J software (National Institutes of Health, USA).

\section{Statistical analysis}

Statistical analysis was performed comparing individual experimental conditions with the control and using
Student's t-test; $\mathrm{P}<0.05$ was considered significant. Data are reported as the average and standard error of measurement. Biological and technical replicates are given in each figure legend. Analyses were performed using GraphPad Prism 5.0 (USA) and Microsoft Excel (USA).

\section{Results}

Mouse MSCs were isolated from adipose tissue and cultivated for three or eight passages before testing cell surface markers. As expected, the MSCs displayed stem cell markers Sca-1 and CD29, but did not present lineagespecific markers CD11b, CD31, or CD45 at passage 3 (Supplementary Figure S1). However, this pattern did not persist at passage eight when Sca-1 staining was reduced (Supplementary Figure S1). Thus, care was taken to use low passage numbers ( 3 to 5 ) for all experiments. The lowpassage MSCs were permissive for differentiation into adipocytes, chondrocytes, and osteocytes (Supplementary Figure S1), confirming that the cell population isolated consisted principally of MSCs.

Next, the MSCs were transduced with the AdRGDPG-eGFP adenoviral vector (non-replicating, serotype 5, RGD fiber modification, PGTx $\beta$ chimeric p53 responsive promoter) and evaluated by flow cytometry. As seen in Figure $1 \mathrm{~A}$, transduction efficiency increased in proportion to the MOI used. Since MOls of 1000 and 2000 did not induce any apparent toxicity, these MOls were tested for the production of IFN $\beta$ upon transduction with the AdRGDPG-IFN $\beta$ virus (Figure 1B). The impact of IFN $\beta$ production on MSC metabolism (viability) was tested using the MTT assay, revealing statistically significant, but limited, reduction in cellular activity (Figure 1C). In contrast, MSCs were sensitive to p19Arf gene transfer (Supplementary Figure S2). These assays showed that MSCs were susceptible to AdRGD transduction, expressed the transgene through the p53-responsive promoter, and were minimally affected by IFN $\beta$ production.

To model MSC-mediated payload delivery, we transduced MSCs with the IFN $\beta$ or LacZ adenoviral vector, AdRGD-CMV-LacZ, then co-cultured these cells along with B16-GFP cells (mouse melanoma with stable expression of eGFP). After $96 \mathrm{~h}$ of incubation at $37^{\circ} \mathrm{C}$, the cells were photographed (as shown in Supplementary Figure S3) and each population (eGFP-negative or positive, indicating MSC or B16, respectively) was counted. We observed that the population of MSCs was not significantly reduced by their transduction with either LacZ or IFN $\beta$ (Figure 2A), yet the co-cultured B16-GFP population was significantly depleted, though this effect required a relatively long incubation period of $96 \mathrm{~h}$ (Figure 2B).

We investigated whether the presence of p19Arf in the B16 melanoma cells would sensitize them to the effects of IFN $\beta$ delivered by the MSCs. In this co-culture assay, the transduction of melanoma cells with AdRGD-PG-p19Arf 

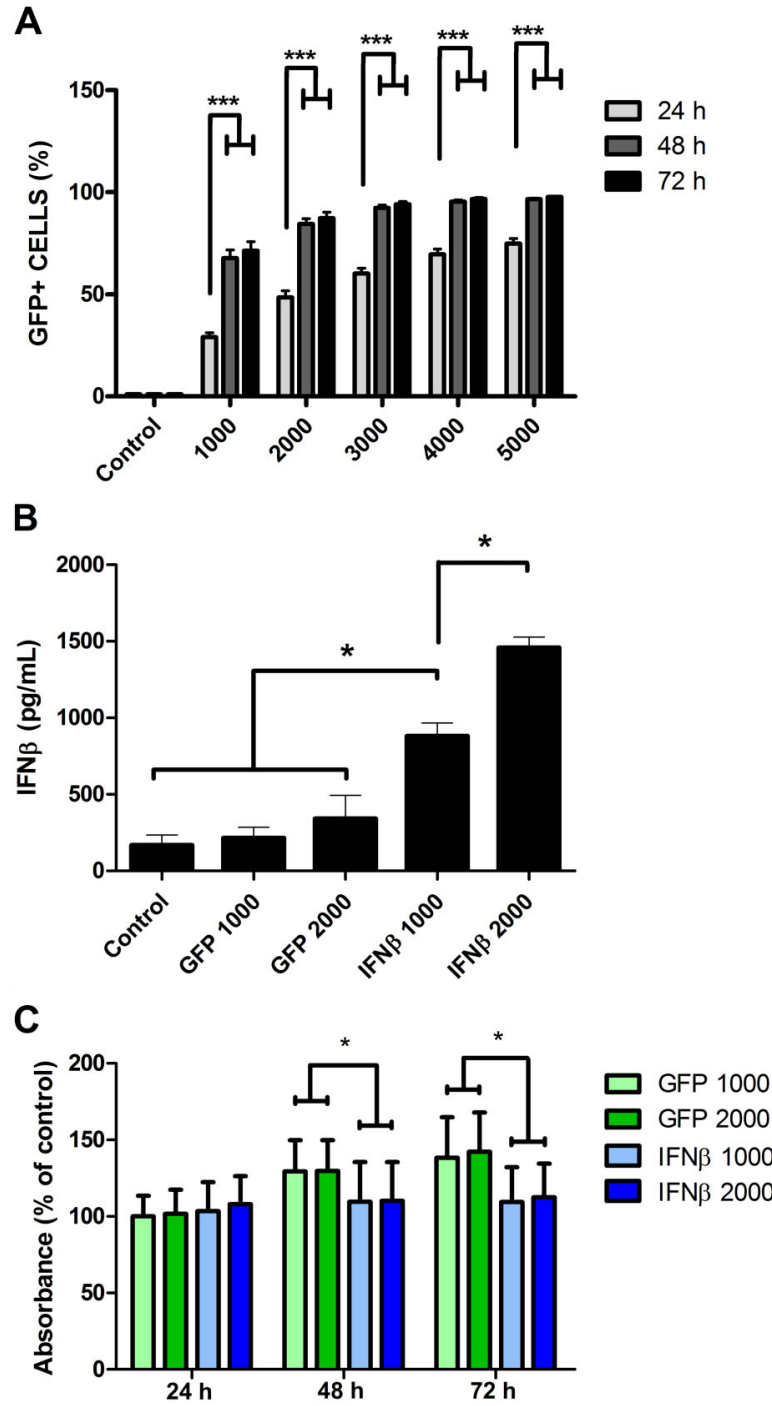

Figure 1. Transduction of mesenchymal stem cells (MSCs) with RGD-modified adenoviral vectors. A, MSCs were either not transduced (Control) or transduced with increasing multiplicity of infection (1000 to 5000) using AdRGD-PG-eGFP and the percentage of green fluorescent protein positive cells (GFP+) was determined by flow cytometry. B, MSCs were transduced using AdRGD-PG-eGFP (GFP) or AdRGD-PG-IFN $\beta$ (IFN $\beta$ ) and, $48 \mathrm{~h}$ later, accumulation of IFN $\beta$ in the supernatant was examined by ELISA. C, Metabolic activity of MSCs was determined by MTT assay 24,48 , or $72 \mathrm{~h}$ post-transduction. Data are reported as the average and standard error of $6(\mathbf{A})$ or 3 (B and $\mathbf{C}$ ) independent assays. ${ }^{*} \mathrm{P}<0.05$, ${ }^{* *} \mathrm{P}<0.001$, statistical analysis was performed comparing individual experimental conditions with the corresponding control using the Student's $t$-test.

yielded essentially complete inhibition in the presence of IFN $\beta$ delivered by MSCs (Figure 3). In comparison, the addition of p19Arf to the tumor cells was insufficient for the blockage of their proliferation when MSCs did not carry

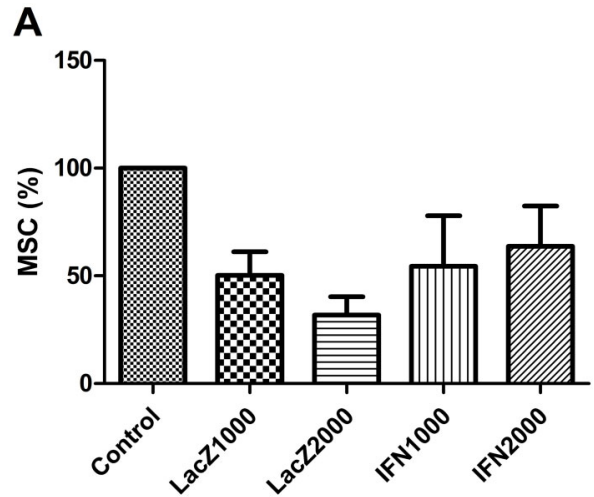

B

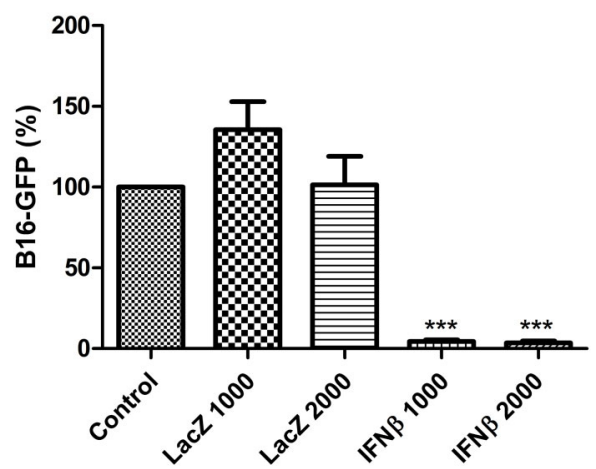

Figure 2. Mesenchymal stem cells (MSCs) producing interferon- $\beta$ (IFN $\beta$ ) inhibited co-cultured B16 mouse melanoma cells. MSCs were either not transduced (Control) or transduced with AdRGDCMV-LacZ (LacZ) or AdRGD-PG-IFN $\beta$ (IFN $\beta$ ) at the indicated multiplicity of infection (1000 or 2000) and then co-cultured with B16 cells with stable expression of eGFP (B16-GFP) and, $96 \mathrm{~h}$ later, each cell population was counted based on the presence or absence of eGFP expression. Quantification of the (A) MSC or (B) B16-GFP populations is reported as the average and standard error from three independent experiments, normalized by the value obtained for the Control group. ${ }^{* * *} \mathrm{P}<0.001$, statistical analysis was performed comparing individual experimental conditions with the control using Student's $t$-test. GFP: green fluorescent protein.

IFN $\beta$. Again, IFN $\beta$ delivered by MSCs did lead to the inhibition of the melanoma cells, but this was more effective in the presence of p19Arf. The presence or absence of the control virus encoding LacZ did not influence the results, indicating that non-specific responses did not play a part in the effect of $p 19 A$ Arf and IFN $\beta$ on the cell populations. These data show that p19Arf sensitizes B16 melanoma cells to IFN $\beta$ delivered by MSCs.

\section{Discussion}

Here, we have shown that MSCs derived from mouse adipose tissue can be modified with our adenoviral vectors and used to deliver a therapeutic payload, IFN $\beta$. 


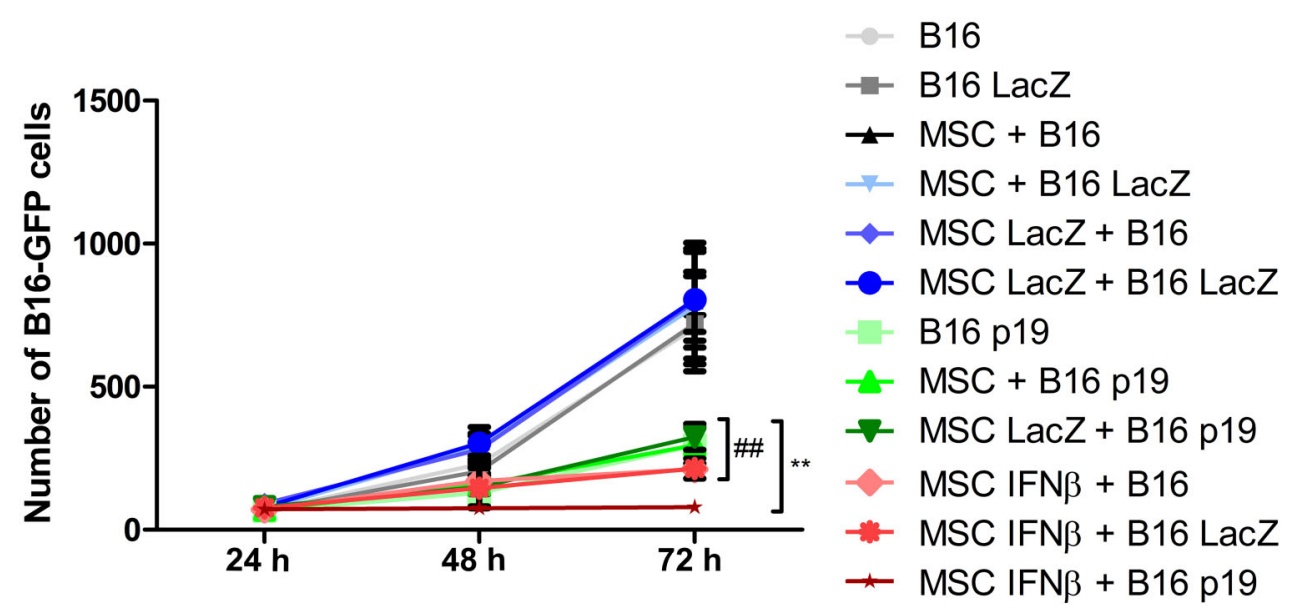

Figure 3. p19Arf sensitizes B16 cells to interferon- $\beta$ (IFN $\beta$ ) produced by mesenchymal stem cells (MSCs). MSCs were either not transduced (MSC) or transduced with AdRGD-CMV-LacZ (MSC LacZ) or AdRGD-PG-IFN $\beta$ (MSC IFN $\beta$ ) and then co-cultured with B16 cells with stable expression of eGFP (B16-GFP) that were also either not transduced (B16) or transduced with either AdRGD-CMV-LacZ (B16 LacZ) or AdRGD-PG-p19 (B16 p19). At the indicated time points, cells were photographed and the B16 cell population was counted based on presence of eGFP expression. Data are reported as the average and standard error from three independent experiments. ${ }^{* *} \mathrm{P}<0.01$ comparing individual experimental conditions with the control (MSC LacZ + B16 LacZ, $72 \mathrm{~h}$ ) using the Student's $t$-test. ${ }^{\#} \mathrm{P}<0.01$ comparing individual experimental conditions with MSC IFN $\beta+$ B16 p19 (72 h) using Student's $t$-test.

This cytokine did not cause extensive killing of the MSCs, yet their production of IFN $\beta$ did inhibit B16 mouse melanoma cells in a co-culture assay. Strikingly, the presence of p19Arf in the B16 cells further sensitized them to the effects of IFN $\beta$ delivered by the MSCs. While this work represents a critical first step and much work remains to be done, we concluded that MSCs can be employed as an interesting component of our combined p19Arf + IFN $\beta$ gene transfer approach.

We propose that use of MSCs as a carrier of IFN $\beta$ may provide advantages over intratumoral gene therapy. In particular, the MSC approach is expected to be transient when applied in vivo, since cells may migrate out of the tumor, differentiate, or die $(9,10)$. The adenovirus that they carry cannot replicate and is not integrated in the host genome, therefore this approach is incompatible with stable, long term exogenous gene expression $(23,24)$. The transient nature of the technology should be sufficient to bring about cell killing and stimulation of an anti-tumor immune response. Though this point remains to be shown experimentally in our model, such responses have been reported (25-29). In addition, unresolved type I interferon signaling may actually be detrimental since it may induce immunosuppression (1), thus limiting the exposure to IFN $\beta$ may be beneficial.

The inclusion of p19Arf in our gene transfer approach is intended to bring about cell death, an outcome that would resolve the issues related to prolonged exposure to IFN $\beta$ and which would provide both antigens and signaling that should contribute to an anti-tumor immune response. In our previous studies, we have noted that either IFN $\beta$ or p19Arf alone can indeed kill tumor cells, yet their combination enhances this effect $(12-14,30)$. In addition, combined, but not individual, gene transfer was associated with the induction of immunogenic cell death $(12,13)$. However, in those assays, p19Arf and IFN $\beta$ were produced by the same cell.

Since IFN $\beta$ is a secreted protein, it need not be produced by the target cell and may exert an effect when provided in a paracrine manner. In a previous study, we have noted that tumor cells producing IFN $\beta$ can kill cocultured, naive tumor cells and that this effect is enhanced in the presence of p19Arf (20). In a recent study, we have shown that transduction of endothelial cells with our AdRGD-PG-IFN $\beta$ does not kill these cells, yet the secretome that they produce does induce death in B16 cells (20), a situation that is quite similar to the one exposed here. However, when the tumor cells produce IFN $\beta$, the endothelial cells are killed by either co-culture or conditioned medium. Moreover, treatment of endothelial cells with recombinant IFN $\beta$ protein does not induce cell death, implying that IFN $\beta$ is not sufficient for killing the endothelial cells (20). While this phenomenon has yet to be studied in the MSC model, the possibility exists that IFN $\beta$ is acting in concert with additional factors produced by the transduced cells.

Clearly, additional work is required to reveal the molecular mechanisms that contribute to tumor cell killing in response to IFN $\beta$ delivered by MSCs and in vivo experiments would shed light on MSC homing to the tumor and its consequences on tumor progression. We propose that, upon treatment, the dynamics within the tumor microenvironment may reveal beneficial anti-tumor responses, including immune activation, inhibition of angiogenesis, 
and induction of cell death. The assays described here represent a point of departure for future studies that may reveal the interplay between gene transfer, cell therapy, and therapeutic transgene activity.

\section{Supplementary Material}

Click here to view [pdf].

\section{Acknowledgments}

We are grateful for the unwavering support of Roger Chammas and colleagues at ICESP, and the animal

\section{References}

1. Medrano RFV, Hunger A, Mendonca SA, Barbuto JAM, Strauss BE. Immunomodulatory and antitumor effects of type I interferons and their application in cancer therapy. Oncotarget 2017; 8: 71249-71284, doi: 10.18632/oncotarget. 19531.

2. Belardelli F, Ferrantini M, Proietti E, Kirkwood JM. Interferonalpha in tumor immunity and immunotherapy. Cytokine Growth Factor Rev 2002; 13: 119-134, doi: 10.1016/S13596101(01)00022-3.

3. Kirkwood JM, Ibrahim JG, Sosman JA, Sondak VK, Agarwala SS, Ernstoff MS, et al. High-dose interferon alfa$2 \mathrm{~b}$ significantly prolongs relapse-free and overall survival compared with the GM2-KLH/QS-21 vaccine in patients with resected stage IIB-III melanoma: results of intergroup trial E1694/S9512/C509801. J Clin Oncol 2001; 19: 2370-2380, doi: 10.1200/JCO.2001.19.9.2370.

4. Kim N, Cho SG. Clinical applications of mesenchymal stem cells. Korean J Intern Med 2013; 28: 387-402, doi: 10.3904/ kjim.2013.28.4.387.

5. Wei W, Huang Y, Li D, Gou HF, Wang W. Improved therapeutic potential of MSCs by genetic modification. Gene Ther 2018; 25: 538-547, doi: 10.1038/s41434-018-0041-8.

6. Studeny M, Marini FC, Champlin RE, Zompetta C, Fidler IJ, Andreeff $M$. Bone marrow-derived mesenchymal stem cells as vehicles for interferon-beta delivery into tumors. Cancer Res 2002; 62: 3603-3608, doi: https://cancerres.aacrjournals. org/content/62/13/3603.long.

7. Ramirez M, Garcia-Castro J, Melen GJ, Gonzalez-Murillo A, Franco-Luzon L. Patient-derived mesenchymal stem cells as delivery vehicles for oncolytic virotherapy: novel state-ofthe-art technology. Oncolytic Virother 2015; 4: 149-155, doi: 10.2147/OV.S66010.

8. Dai LJ, Moniri MR, Zeng ZR, Zhou JX, Rayat J, Warnock GL. Potential implications of mesenchymal stem cells in cancer therapy. Cancer Lett 2011; 305: 8-20, doi: 10.1016/ j.canlet.2011.02.012.

9. Nakashima H, Kaur B, Chiocca EA. Directing systemic oncolytic viral delivery to tumors via carrier cells. Cytokine Growth Factor Rev 2010; 21: 119-126, doi: 10.1016/ j.cytogfr.2010.02.004.

10. Zhang Q, Xiang W, Yi DY, Xue BZ, Wen WW, Abdelmaksoud $A$, et al. Current status and potential challenges of mesenchymal stem cell-based therapy for malignant gliomas. facility at the Centro de Medicina Nuclear (CMN), FMUSP. We are indebted to Mariz Vainzof and Marina Garcia Ribeiro, Centro de Estudos do Genoma Humano, Instituto de Biosciencias, USP, for critical support in establishing MSC cultures. Financial support was provided by the Sao Paulo Research Foundation (FAPESP), grants 13/251675, 15/26580-9 (BES), and fellowships 16/18197-3 (IVL), $11 / 10656-5(\mathrm{AH})$, and $11 / 21256-8$ (RET). This study was financed in part by the Coordenação de Aperfeiçoamento de Pessoal de Nível Superior, Brasil (CAPES), Finance Code 001 (RCC).

Stem Cell Res Ther 2018; 9: 228, doi: 10.1186/s13287-0180977-z.

11. Marofi F, Vahedi G, Biglari A, Esmaeilzadeh A, Athari SS. Mesenchymal stromal/stem cells: a new era in the cellbased targeted gene therapy of cancer. Front Immunol 2017; 8: 1770, doi: 10.3389/fimmu.2017.01770.

12. Catani JPP, Medrano RFV, Hunger A, Del Valle P, Adjemian $S$, Zanatta DB, et al. Intratumoral immunization by p19Arf and interferon-beta gene transfer in a heterotopic mouse model of lung carcinoma. Transl Oncol 2016; 9: 565-574, doi: 10.1016/j.tranon.2016.09.011.

13. Hunger A, Medrano RF, Zanatta DB, Del Valle PR, Merkel CA, Salles TA, et al. Reestablishment of p53/Arf and interferon-beta pathways mediated by a novel adenoviral vector potentiates antiviral response and immunogenic cell death. Cell Death Discov 2017; 3: 17017, doi: 10.1038/cd discovery.2017.17.

14. Medrano RF, Catani JP, Ribeiro AH, Tomaz SL, Merkel CA, Costanzi-Strauss $\mathrm{E}$, et al. Vaccination using melanoma cells treated with p19arf and interferon beta gene transfer in a mouse model: a novel combination for cancer immunotherapy. Cancer Immunol Immunother 2016; 65: 371-382, doi: 10.1007/s00262-016-1807-8.

15. Weber JD, Taylor LJ, Roussel MF, Sherr CJ, Bar-Sagi D. Nucleolar Arf sequesters Mdm2 and activates p53. Nat Cell Biol 1999; 1: 20-26, doi: 10.1038/8991.

16. Takaoka A, Hayakawa S, Yanai $H$, Stoiber D, Negishi $H$, Kikuchi $\mathrm{H}$, et al. Integration of interferon-alpha/beta signalling to p53 responses in tumour suppression and antiviral defence. Nature 2003; 424: 516-523, doi: 10.1038/nature 01850.

17. Sandoval R, Xue J, Pilkinton M, Salvi D, Kiyokawa $H$, Colamonici OR. Different requirements for the cytostatic and apoptotic effects of type I interferons. Induction of apoptosis requires ARF but not p53 in osteosarcoma cell lines. J Biol Chem 2004; 279: 32275-32280, doi: 10.1074/jbc.M313830200.

18. Hunger A, Medrano RF, Strauss BE. Harnessing combined p19Arf and interferon-beta gene transfer as an inducer of immunogenic cell death and mediator of cancer immunotherapy. Cell Death Dis 2017; 8: e2784, doi: 10.1038/ cddis.2017.201.

19. Medrano RFV, Hunger A, Catani JPP, Strauss BE. Uncovering the immunotherapeutic cycle initiated by p19Arf and 
interferon-beta gene transfer to cancer cells: An inducer of immunogenic cell death. Oncoimmunology 2017; 6: e1329072, doi: 10.1080/2162402X.2017.1329072.

20. Vieira IL, Tamura RE, Hunger A, Strauss BE. Distinct roles of direct transduction versus exposure to the tumor secretome on murine endothelial cells after melanoma gene therapy with interferon-beta and p19Arf. J Interferon Cytokine Res 2019; 39: 246-258, doi: 10.1089/jir.2018.0124.

21. Mizuguchi $\mathrm{H}$, Koizumi N, Hosono T, Utoguchi $\mathrm{N}$, Watanabe $\mathrm{Y}$, Kay MA, et al. A simplified system for constructing recombinant adenoviral vectors containing heterologous peptides in the $\mathrm{HI}$ loop of their fiber knob. Gene Ther 2001; 8: 730-735, doi: 10.1038/sj.gt.3301453.

22. Peng HH, Wu S, Davis JJ, Wang L, Roth JA, Marini FC 3rd, et al. A rapid and efficient method for purification of recombinant adenovirus with arginine-glycine-aspartic acid-modified fibers. Anal Biochem 2006; 354: 140-147, doi: 10.1016/ j.ab.2006.04.032.

23. Strauss BE, Costanzi-Strauss E. Gene therapy for melanoma: progress and perspectives. In: Davids LM, editor. Recent advances in the biology, therapy and management of melanoma: InTech Open Science; 2013, doi: 10.5772/54936.

24. Strauss BE, Silva GRO, de Luna Vieira I, Cerqueira OLD, Del Valle PR, Medrano RFV, et al. Perspectives for cancer immunotherapy mediated by p19Arf plus interferon-beta gene transfer. Clinics 2018; 73: e479s, doi: 10.6061/clinics/ 2018/e479s.

25. Choi SH, Stuckey DW, Pignatta S, Reinshagen C, Khalsa JK, Roozendaal N, et al. Tumor resection recruits effector $t$ cells and boosts therapeutic efficacy of encapsulated stem cells expressing IFNbeta in Glioblastomas. Clin Cancer Res 2017; 23: 7047-7058, doi: 10.1158/1078-0432. CCR-17-0077.

26. Su Y, Cheng R, Zhang J, Qian J, Diao C, Ran J, et al. Interferon-alpha2b gene-modified human bone marrow mesenchymal stem cells inhibit hepatocellular carcinoma by reducing the Notch1 levels. Life Sci 2015; 143: 18-26, doi: 10.1016/j.Ifs.2015.10.031.

27. Xu G, Guo Y, Seng Z, Cui G, Qu J. Bone marrow-derived mesenchymal stem cells co-expressing interleukin-18 and interferon-beta exhibit potent antitumor effect against intracranial glioma in rats. Oncol Rep 2015; 34: 1915-1922, doi: 10.3892/or.2015.4174.

28. Park JH, Ryu CH, Kim MJ, Jeun SS. Combination therapy for gliomas using temozolomide and interferon-beta secreting human bone marrow derived mesenchymal stem cells. J Korean Neurosurg Soc 2015; 57: 323-328, doi: 10.3340/ jkns.2015.57.5.323.

29. Xie C, Xie DY, Lin BL, Zhang GL, Wang PP, Peng L, et al. Interferon-beta gene-modified human bone marrow mesenchymal stem cells attenuate hepatocellular carcinoma through inhibiting AKT/FOXO3a pathway. Br J Cancer 2013; 109: 1198-1205, doi: 10.1038/bjc.2013.422.

30. Merkel CA, Medrano RF, Barauna VG, Strauss BE. Combined p19Arf and interferon-beta gene transfer enhances cell death of B16 melanoma in vitro and in vivo. Cancer Gene Ther 2013; 20: 317-325, doi: 10.1038/cgt. 2013.23. 